\title{
CrystEngComm
}

Check for updates

Cite this: CrystEngComm, 2019, 21, 145

Received 10th October 2018,

Accepted 1st December 2018

DOI: $10.1039 / c 8 c e 01726 c$

rsc.li/crystengcomm

\section{On the structural stability of crystalline ceria phases in undoped and acceptor-doped ceria materials under in situ reduction conditions $\dagger$}

\author{
Maged F. Bekheet, (D) a Matthias Grünbacher, ${ }^{b}$ Lukas Schlicker, (iD) a Albert Gili, (D) a \\ Andrew Doran, iD c Jan Dirk Epping, ${ }^{\mathrm{d}}$ Aleksander Gurlo, iD ${ }^{\mathrm{a}}$ \\ Bernhard Klötzer ${ }^{b}$ and Simon Penner iD *b
}

\begin{abstract}
The reduction of pure and Sm-doped ceria in hydrogen has been studied by synchrotron-based in situ $X$-ray diffraction to eventually prove or disprove the presence of crystalline cerium hydride $\left(\mathrm{CeH}_{x}\right)$ phases and the succession of potential structural phase (trans)formations of reduced cerium oxide phases during heating-cooling cycles up to $1273 \mathrm{~K}$. Despite a recent report on the existence of bulk and surface $\mathrm{CeH}_{x}$ phases during reductive treatment of pure $\mathrm{CeO}_{2}$ in $\mathrm{H}_{2}$, structural analysis by Rietveld refinement as well as additional ${ }^{1} \mathrm{H}$-NMR spectroscopy did not reveal the presence of any crystalline $\mathrm{CeH}_{x}$ phase. Rather, a sequence of phase transformations during the re-cooling process in $\mathrm{H}_{2}$ has been observed. In both samples, the reduced/defective fluorite lattice undergoes at first a transformation into a bixbyite-type lattice with a formal stoichiometry $\mathrm{Ce}_{0.58}{ }^{3+} \mathrm{Ce}_{0.42}{ }^{4+} \mathrm{O}_{1.71}$ and $\mathrm{Sm}_{0.15}{ }^{3+} \mathrm{Ce}_{0.39}{ }^{3+} \mathrm{Ce}_{0.46}{ }^{4+} \mathrm{O}_{1.73}$, before a transformation into rhombohedral $\mathrm{Ce}_{7} \mathrm{O}_{12}$ takes place in pure $\mathrm{CeO}_{2}$. This phase is clearly absent for the $\mathrm{Sm}$-doped material. Finally, a triclinic $\mathrm{Ce}_{11} \mathrm{O}_{20}$ phase appears for both materials, which can be recovered to room temperature, and on which a phase mixture of bixbyite $\mathrm{Ce}_{0.66}{ }^{3+} \mathrm{Ce}_{0.34}{ }^{4+} \mathrm{O}_{1.67}, \mathrm{rh}-\mathrm{Ce}_{0.60}{ }^{3+} \mathrm{Ce}_{0.40}{ }^{4+} \mathrm{O}_{1.70}$ and tri$\mathrm{Ce}_{0.48}{ }^{3+} \mathrm{Ce}_{0.52}{ }^{4+} \mathrm{O}_{1.76}$ (for pure $\mathrm{CeO}_{2}$ ) or bixbyite $\mathrm{Sm}_{0.15}{ }^{3+} \mathrm{Ce}_{0.47}{ }^{3+} \mathrm{Ce}_{0.38}{ }^{4+} \mathrm{O}_{1.69}$ and tri$\mathrm{Sm}_{0.15}{ }^{3+} \mathrm{Ce}_{0.31}{ }^{3+} \mathrm{Ce}_{0.54}{ }^{4+} \mathrm{O}_{1.77}$ (for $\mathrm{Sm}$-doped $\mathrm{CeO}_{2}$ ) prevails. The absence of the rhombohedral phase indicates that $\mathrm{Sm}$ doping leads to the stabilization of the bixbyite phase over the rhombohedral one at this particular oxygen vacancy concentration. It is worth noting that recent work proves that hydrogen is indeed incorporated within the structures during the heat treatments, but under the chosen experimental conditions it has apparently no effect on the salient structural principles during reduction.
\end{abstract}

\section{Introduction}

Ceria $\left(\mathrm{CeO}_{2}\right)$ and ceria-based oxides are among the most commonly employed promoting catalyst components and support materials for metal particles that can be found in the commercial industrial sector. ${ }^{1}$ Three-way catalysts for exhaust gas control are based on ceria as the material provides a high oxygen storage capacity. ${ }^{2-4}$ Supports for catalysts used for hydrocarbon $^{5}$ or CO (ref. 6) oxidation are often made of ceria. Fur-

\footnotetext{
${ }^{a}$ Fachgebiet Keramische Werkstoffe/Chair of Advanced Ceramic Materials, Institut für Werkstoffwissenschaften und -technologien, Technische Universität Berlin, Hardenbergstr. 40, 10623 Berlin, Germany

${ }^{b}$ Institute of Physical Chemistry, University of Innsbruck, Innrain 52c, A-6020 Innsbruck, Austria. E-mail: simon.penner@uibk.ac.at; Tel: +4351250758003 ${ }^{c}$ Advanced Light Source, Lawrence Berkeley National Laboratory Berkeley, California 94720, USA

${ }^{d}$ Fakultät II : Mathematik \& Naturwissenschaften, Institut für Chemie, Technische Universität Berlin, Hardenbergstr. 40, 10623 Berlin, Germany

$\dagger$ Electronic supplementary information (ESI) available. See DOI: 10.1039/ c8ce01726c
}

thermore, ceria catalysts provide an economic way for the production of PEMFC grade $\mathrm{H}_{2}$ via water-gas shift reaction and subsequent processing by the preferential oxidation of $\mathrm{CO}$ in a $\mathrm{H}_{2}$-rich atmosphere. ${ }^{7-9}$ Also, good activity for dehydrogenation/dehydration of alcohols, the decomposition of aldehydes and, recently, the hydrogenation of alkynes to alkenes was attested to ceria catalysts. ${ }^{10-13}$

Doped ceria oxides can also be used in SOFC and SOEC construction. For this purpose, Gd- and Sm-doping is preferred, as it increases the oxide ion conductivity of pure $\mathrm{CeO}_{2}$ significantly. ${ }^{14}$ Moreover, the efficiency of proton ceramic fuel cells can be increased by expanding the reactive zone for water formation on the cathode side. ${ }^{15}$ Co-sintering of $\mathrm{Gd}_{0.15} \mathrm{Ce}_{0.85} \mathrm{O}_{2-\delta}$ and $\mathrm{BaCe}_{0.65} \mathrm{Zr}_{0.20} \mathrm{Y}_{0.15} \mathrm{O}_{3-\delta}$ is also possible, enabling the production of mixed protonic and electronic conducting composite ceramics with favourable properties for $\mathrm{H}_{2}$ separation membranes. ${ }^{16}$

The previous paragraphs list some of the most important applications of ceria and variations of ceria and make it clear that these materials are often in contact with hydrogen at 
elevated temperatures. Therefore, the system $\mathrm{CeO}_{2}-\mathrm{H}_{2}$ attracted a lot of scientific attention in the past. Ex situ X-ray diffraction and elastic neutron scattering were employed to identify and describe the structure of reduced ceria phases. ${ }^{17-21}$ Meticulous analysis of the acquired data led to the conclusion that many $\mathrm{O}$ deficient phases exhibit $\mathrm{O}$ vacancy ordering which leads to superstructure reflexes in diffraction patterns. ${ }^{17}$ The chemical formula of $\mathrm{O}$ vacancy ordered phases of reduced ceria obeys a homologous series of the form $\mathrm{Ce}_{n} \mathrm{O}_{2 n-2} \cdot{ }^{17}$ An example would be $\mathrm{Ce}_{7} \mathrm{O}_{12}$, where $\mathrm{O}$ vacancies are ordered along the room diagonal of the stringed unit cells. ${ }^{19,20}$ Interestingly, the formation of $\mathrm{O}$ vacancy ordered phases appears to be common for rare earth oxides such as $\mathrm{CeO}_{2-x}, \mathrm{PrO}_{2-x}$ and $\mathrm{TbO}_{2-x}{ }^{19}$ However, most of these results stem from ex situ X-ray diffraction and elastic neutron scattering studies, which do not provide access to the phases formed at different conditions of temperature and atmosphere during the catalytic reactions between the catalyst and the gas phase. Thus, in situ XRD studies are highly required. Interestingly, the $\mathrm{Ce}_{7} \mathrm{O}_{12}$ structure has been also prepared recently on a so called "inverse" model catalyst following thermal reduction of $\mathrm{CeO}_{2}$ islands without hydrogen, particularly raising the question what role the hydrogen plays in the reduction process as well as the formation of hydroxyl entities. $^{22}$

Another aspect to consider in a $\mathrm{CeO}_{2}-\mathrm{H}_{2}$ system is the incorporation of hydrogen in the oxide bulk as was shown e.g. in ref. 23. This important question was discussed in the past and many authors contributed to the topic up to the present day, employing different approaches. The existence of bulkabsorbed hydrogen in $\mathrm{CeO}_{2}$ was derived from results acquired by ${ }^{1} \mathrm{H} \mathrm{NMR},{ }^{24}$ nuclear reaction analysis, ${ }^{13}$ deuterium-hydrogen exchange, ${ }^{25}$ infrared spectroscopy, ${ }^{26}$ inelastic neutron scattering $^{27}$ and temperature-programmed reduction ${ }^{28}$ and is supported by theory as well. ${ }^{29,30}$ While the hydrogen dissolution in $\mathrm{CeO}_{2}$ has been accepted by most authors, the chemical nature of incorporated hydrogen is still under dispute. ${ }^{1} \mathrm{H}$ NMR is a promising method for studying ceria-bonded hydrogen. In a paper by Lyons et al. ${ }^{1} \mathrm{H}$ MAS NMR was used to study hydrogen adsorption on nonporous and mesoporous ceria. ${ }^{31}$ It was shown that ceria is an extremely advantageous oxide for solid state NMR of hydrogen as exceptionally sharp magnetic ${ }^{1} \mathrm{H}$ resonances can be obtained. ${ }^{31}$ The resolution is even high enough to discern on top and bridged $\mathrm{OH}$ groups. ${ }^{31}$ Also, a combination of thermogravimetry and ${ }^{1} \mathrm{H}$ NMR suggested hydrogen occlusion in $\mathrm{CeO}_{2} \cdot{ }^{32}$

The presence of dissolved hydrogen in ceria and its impact on catalysis has been discussed in the last years. $\mathrm{H}_{2}$-reduced Ni-doped $\mathrm{CeO}_{2}$ (and derived oxides) was shown to hold a catalytically active hydrogen reservoir for hydrogenation of alkenes. $^{33,35}$ Works like Jolawiecki-Duhamel's aim particularly in the elucidation of the mechanism of reactions involving the catalytic transfer of incorporated hydrogen from ceria. $^{34}$ The hydrogen reservoirs are speculated to consist of oxyhydrides - which has also been called bronze-like $\mathrm{H}_{y} \mathrm{CeO}_{2-x}$ in earlier works ${ }^{24,26}$ - or, alternatively, pure hydrides $\mathrm{CeH}_{x}$ as implied by inelastic neutron scattering. ${ }^{27,33}$
Formation of $\mathrm{CeO}_{2} \mathrm{H}_{y}$ entities have also been proposed by Matsukawa et $a l^{36}$ following hydrogen treatments at very short contact times - necessarily without a high vacancy concentration.

As has been shown, extensive work concerning structural aspects, hydrogen incorporation and catalysis focused on $\mathrm{H}_{2}-$ reduced $\mathrm{CeO}_{2}$ has been accumulated over the past years. However, the incorporation of hydrogen in acceptor-doped ceria materials, such as SDC15 $\left(\mathrm{Sm}_{0.15} \mathrm{Ce}_{0.85} \mathrm{O}_{2-\delta}\right)$ was neglected so far. To the best of our knowledge only one work tested the dissolution of hydrogen in SDC20 by secondary ion mass spectroscopy after annealing the oxides in $\mathrm{D}_{2} \mathrm{O}$ (and not under reducing conditions). ${ }^{37}$ Of particular importance is also answering the question, whether on doped ceria materials - in comparison to undoped $\mathrm{CeO}_{2}$ - crystalline cerium or mixed hydride phases are observed. No unambiguous experimental evidence has been found up to now for an oxygen-free $\mathrm{CeH}_{x}$ hydride phase. ${ }^{27}$ As the stability of the hydrides potentially is a strong function of the reduction potential of the gas phase, the present work's first objective was to test the crystallographic impact of oxygen extraction from and hydrogen dissolution in pure $\mathrm{CeO}_{2}$ and Sm-doped ceria - in an $\mathrm{H}_{2}$ atmosphere and at elevated temperatures - by in situ XRD. We chose in situ XRD as the ex situ studies might not provide access to intermediate/metastable phases formed at different conditions of temperature and atmosphere. The in situ synchrotron XRD experiments allow us to follow the crystalline structure of the materials that is a basic feature for chemical and mechanical properties and is therefore of key importance for the oxide's applications. ${ }^{18}$ The second point of interest is concerned with the elucidation of the occluded hydrogen's chemical nature for which we used solid state ${ }^{1} \mathrm{H}$ NMR.

\section{Experimental}

Pure and Sm-doped $\mathrm{CeO}_{2}$ micron and nano-powders with a purity of 99.9\% were purchased form Alfa Aesar and SigmaAldrich, respectively. The Sm-containing sample has a stoichiometry of $\mathrm{Sm}_{0.15} \mathrm{Ce}_{0.85} \mathrm{O}_{2-\delta}$ and is subsequently labeled as SDC15. The samples were initially calcined at $1273 \mathrm{~K}$ in air, respectively, and afterwards the BET surface area was determined. For SDC15, BET analysis in a surface and pore analyser Nova 2000e from Quantachrome yielded a surface area of $4.7 \mathrm{~m}^{2} \mathrm{~g}^{-1}$ after calcination. Structural changes of the oxides that might have been caused by thermal annealing were excluded by ex situ XRD prior to the actual in situ characterization. Accordingly, the samples were not heated above the initial calcination temperature during the experiments.

The in situ high-temperatures synchrotron XRD experiments in $\mathrm{O}_{2}$ or $\mathrm{H}_{2}$ were performed at beamline 12.2.2, Advanced Light Source, Lawrence Berkeley National Labs, California. The in situ diffraction patterns were collected in the angle-dispersive transmission mode with a focused $25 \mathrm{keV}$ monochromatic beam $(\lambda=0.4957 \AA / 50 \mu \mathrm{m}$ spot size). The sample powder was heated in $0.7 \mathrm{~mm}$ quartz capillaries under a continuous gas flow $\left(\mathrm{O}_{2}\right.$ or $\left.\mathrm{H}_{2}\right)$ injected through 
another $0.5 \mathrm{~mm}$ capillary with a cut-open end. The capillary is heated in an infrared heated $\mathrm{SiC}$ tube furnace as described in elsewhere. ${ }^{38,39}$ Diffraction patterns were recorded by a PerkinElmer flat panel detector (XRD 1621, dark image and strain correction) every 25 seconds during the heating and cooling cycle. To remove any organic or volatile materials from the samples and ensure identical starting points for the subsequent determination of the oxygen nonstoichiometry, an oxidative pre-treatment in flowing $\mathrm{O}_{2}\left(0.8 \mathrm{~mL} \mathrm{~s}^{-1} / 1\right.$ bar $)$ at $1023 \mathrm{~K}$ for $30 \mathrm{~min}$ was first employed for all samples. The samples then were reduced in the flowing $\mathrm{H}_{2}(1 \mathrm{~mL} \mathrm{~s} / 1 \mathrm{bar})$ between $300-1273 \mathrm{~K}$ with isothermal step at $1273 \mathrm{~K}$ for 10 min. Finally, all reduced samples were re-oxidized again in flowing $\mathrm{O}_{2}\left(1.0 \mathrm{~mL} \mathrm{~s}{ }^{-1} / 1\right.$ bar $)$ between $300-1273 \mathrm{~K}$ with isothermal step at $1273 \mathrm{~K}$ for $10 \mathrm{~min}$. The heating and cooling rates were $25 \mathrm{~K} \mathrm{~min}^{-1}$ for all experiments. Rietveld refinement was performed using the FULLPROF program. ${ }^{40}$ The profile function 7 (Thompson-Cox-Hastings pseudo-Voigt convoluted with axial divergence asymmetry function $)^{41}$ was used in all refinements. The structure parameters of the respective starting model of fluorite $\mathrm{CeO}_{2}$, bixbyite b-Ce $\mathrm{O}_{3+\delta^{\prime}}$, rh- $\mathrm{Ce}_{7} \mathrm{O}_{12}$ and tri-Ce ${ }_{11} \mathrm{O}_{20}$ for Rietveld refinement were taken from literature. ${ }^{18}$

${ }^{1} \mathrm{H}$ Solid state NMR spectra were recorded with a Bruker Avance $400 \mathrm{MHz}$ spectrometer operating at $399.88 \mathrm{MHz} 1 \mathrm{H}$. The NMR experiments were carried out at a MAS rate of 10 $\mathrm{kHz}$ using a $4 \mathrm{~mm}$ MAS $\mathrm{HX}$ double resonance probe. The ${ }^{1} \mathrm{H}$ $\pi / 2$ pulse length was $5.0 \mu$ s and the spectra were measured using a recycle delay of $2 \mathrm{~s}$. All spectra are referenced to external tetramethylsilane (TMS) at 0 ppm using adamantane as a secondary reference.

\section{Results and discussion}

As shown in Fig. S1 in the ESI, $\dagger$ the XRD pattern of the starting SDC15 and $\mathrm{CeO}_{2}$ specimens before any gas treatment can be fitted well with the calculated pattern corresponding to the fluorite structure of pure $\mathrm{CeO}_{2}\left(F m \overline{3} m\right.$, No. 225). ${ }^{42}$ No superstructure reflections are observed in the XRD pattern of SDC15, which suggests a random substitution of $\mathrm{Sm}^{3+}$ cations in the $\mathrm{CeO}_{2}$ lattice. The substitution of larger $\mathrm{Sm}^{3+}$ for smaller $\mathrm{Ce}^{4+}$ cations in the fluorite structure $\left[r\left(\mathrm{Sm}^{3+}\right)=1.079\right.$ $\AA, r\left(\mathrm{Ce}^{4+}\right)=0.970 \AA$; all cations are 8 -fold coordinated $]^{43}$ is further confirmed by Rietveld refinement, that reveals an increase in the lattice parameter of SDC15 $(a=5.4269 \pm 0.0001$ $\AA)$ in comparison with that of undoped $\mathrm{CeO}_{2}(a=5.4081 \pm$ $0.0001 \AA)$. The amount of $\mathrm{Sm}^{3+}$ cations $x$ incorporated into the $\mathrm{CeO}_{2}$ lattice, as well as the resulting oxygen vacancies parameter $\delta$ in the fluorite-type $\mathrm{Sm}_{x} \mathrm{Ce}_{1-x} \mathrm{O}_{2-\delta}$ structure can be estimated from the difference in the lattice parameter between the undoped and doped $\mathrm{CeO}_{2-\delta}$, according the relationship: ${ }^{44}$

$$
a_{\text {doped }}-a_{\text {undoped }}=\frac{4}{\sqrt{3}}\left[r_{\mathrm{M}^{3+}}-r_{\mathrm{Ce}^{4+}}-0.25 r_{0}+0.25 r_{v_{0}}\right] x
$$

where $r_{\mathrm{M}^{3+}}, r_{\mathrm{Ce}^{4+}}, r_{\mathrm{O}}$ and $r_{v_{\mathrm{O}}}$ are the ionic radii of the trivalent dopant cation, $\mathrm{Ce}^{4+}$, the oxygen ion and the oxygen vacancy, respectively. By using $r_{\mathrm{O}}=1.38 \AA$ and $r_{\nu \mathrm{O}}=1.164 \AA$, the mole fractions $x$ of $\mathrm{Sm}^{3+}$ and oxygen vacancy parameter $\delta$ (i.e. $\delta=x / 2$ ) in SDC15 are found to be 0.148 - which is in good agreement with the value specified by the manufacturer $(x=$ 0.15 ) - and 0.074 , respectively. This result suggests the chemical formula $\mathrm{Sm}_{0.148} \mathrm{Ce}_{0.852} \mathrm{O}_{1.926}$ for SDC15 sample.

To compare the reduction behaviour of $\mathrm{CeO}_{2}$ and SDC15, temperature-programmed in situ XRD measurements were conducted in flowing hydrogen (Fig. 1). In situ XRD experiments on both specimens were performed first under $\mathrm{O}_{2}$ atmosphere to ensure that the chemical composition and crystal structure are stable before the temperature-programmed reduction step. As shown in Fig. S2 (ESI $\dagger$ ), the fluorite structure of both specimens remains stable up to $1023 \mathrm{~K}$ under $\mathrm{O}_{2}$ atmosphere. In contrast, despite both samples maintain also the fluorite structure during heating up to $1273 \mathrm{~K}$ in $\mathrm{H}_{2}$ atmosphere, several consecutive phase changes are observed during the cooling cycle (Fig. 1). In case of pure $\mathrm{CeO}_{2}$ (Fig. 1A and B), the fluorite structure is first transformed into the bixbyite-type structure b-Ce $\mathrm{O}_{3+\delta^{\prime}}$ or b-CeO $\mathrm{Ce}_{2-\delta}$ (PDF-card \#01-089-8430) at around $1228 \mathrm{~K}$, which remains stable before transforming partially into rhombohedral rh- $\mathrm{Ce}_{7} \mathrm{O}_{12}$ (PDFcard \#01-089-8433) at $924 \mathrm{~K}$ and then triclinic tri- $\mathrm{Ce}_{11} \mathrm{O}_{20}$ (PDF-card \#01-089-8435) at $800 \mathrm{~K}$. For the SDC15 specimen (Fig. 1C and D), the fluorite $\rightarrow$ bixbyite phase transformation is also observed, but at slightly higher temperature (i.e. 1263 K) compared to pure $\mathrm{CeO}_{2}$. Moreover, the bixbyite structure is transformed to only tri- $\mathrm{Ce}_{11} \mathrm{O}_{20}$ at $715 \mathrm{~K}$, which is lower than the transition temperature of the same phase transformation observed in the pure $\mathrm{CeO}_{2}$ sample. A more detailed discussion will be provided below.

The structure refinement of the samples cooled to room temperature reveals that the reduced pure $\mathrm{CeO}_{2}$ sample consists of 12.1(0.7) wt $\% \mathrm{~b}-\mathrm{CeO}_{2-\delta}, 62.4(0.8) \mathrm{wt} \% \mathrm{rh}-\mathrm{Ce}_{7} \mathrm{O}_{12}$ and 25.5(0.6) wt $\%$ tri- $\mathrm{Ce}_{11} \mathrm{O}_{20}$, while the reduced SDC15 contains only 78.8(0.7) wt\% b-CeO $\mathrm{CeO}_{2-\delta}$ and 21.2(0.6) wt\% tri-Ce ${ }_{11} \mathrm{O}_{20}$. The weight fractions of all phases formed at different temperatures during cooling of $\mathrm{CeO}_{2}$ and SDC15 samples in $\mathrm{H}_{2}$ atmosphere are shown in Fig. 2.

The lattice parameter's temperature dependence of the observed crystalline phases is very important to understand the expansion of the lattice due to thermal influences as well as chemical changes (i.e. removing oxygen from the lattice or reduction of $\mathrm{Ce}^{4+}$ into $\mathrm{Ce}^{3+}$ cations). Accordingly, the lattice parameters of the fluorite phases and the pseudo-cubic lattice parameters of the other phases formed in both $\mathrm{CeO}_{2}$ and SDC15 samples are determined by structure refinement and plotted as function of temperature in Fig. $3 \mathrm{~A}$ and $\mathrm{B}$. It can be clearly seen, that the temperature dependence of the lattice parameter of the fluorite $\mathrm{CeO}_{2}$ phase in both specimens is linear over the entire temperature range of the experiments during heating and cooling in $\mathrm{O}_{2}$ atmosphere, which can be explained by the linear thermal expansion of both materials. In contrast, the lattice parameter in both specimens heated 

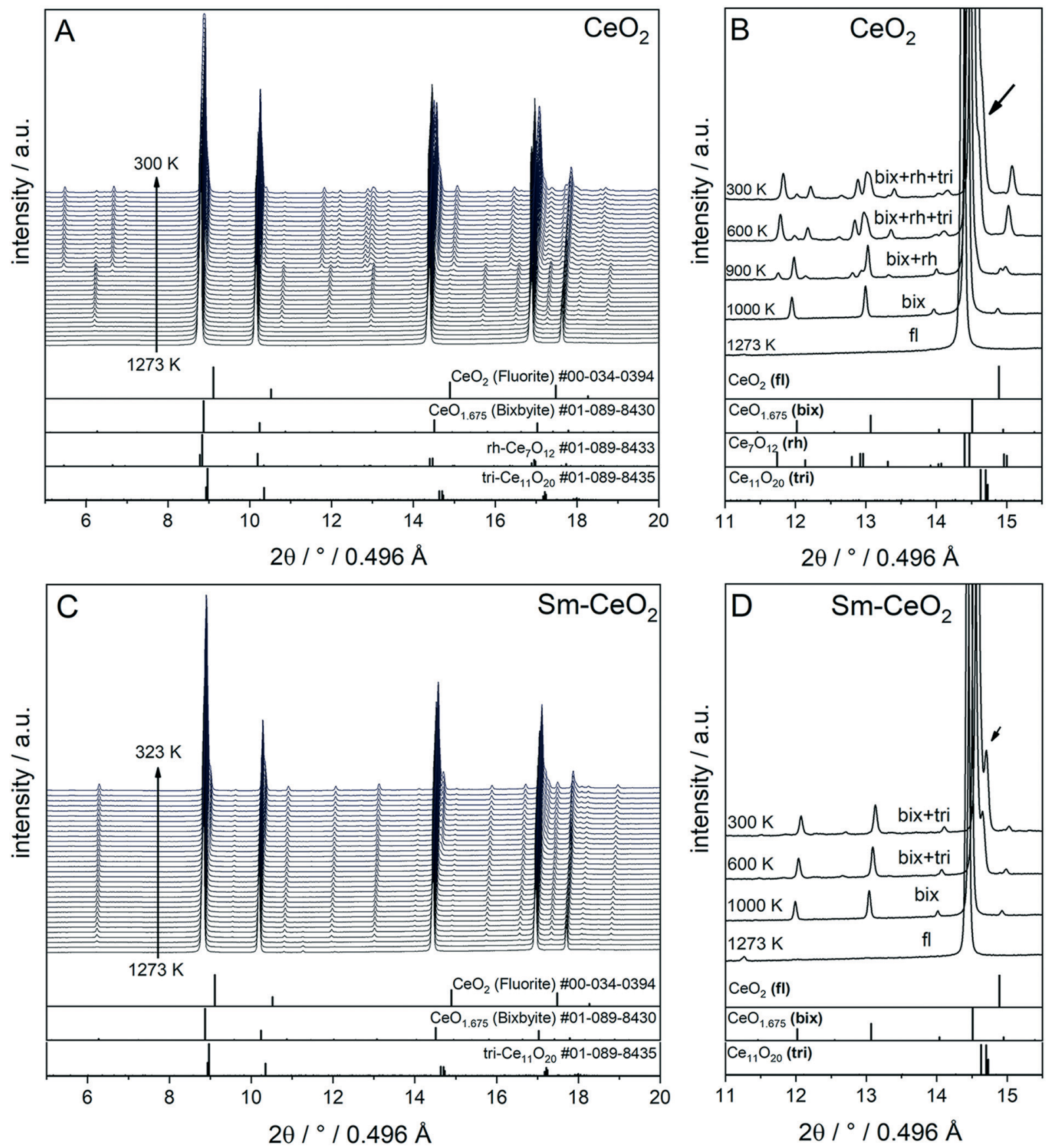

Fig. 1 In situ XRD patterns $\left(\lambda=0.4957 \AA\right.$ ) collected during cooling of $\mathrm{CeO}_{2}$ (A and B) and SDC15 (C and D) specimens from $1273 \mathrm{~K}$ under hydrogen flow. Panel $A$ and $C$ show the in situ XRD patterns in a broad $2 \Theta$ range and in a temperature interval between 300 and $1273 \mathrm{~K}$. Panels $\mathrm{B}$ and $D$ focus on a narrower $2 \Theta$ window for closer analysis. The calculated diffraction patterns of the fluorite $\mathrm{CeO}_{2}, \mathrm{bixbyite} \mathrm{CeO}_{1.675}, \mathrm{rh}_{-} \mathrm{Ce}_{7} \mathrm{O}_{12}$ and tri- $\mathrm{Ce}_{11} \mathrm{O}_{20}$ structures are shown at the bottom. The arrow in Fig. $\mathrm{B}$ and $\mathrm{D}$ indicates the reflections of triclinic tri-Ce $\mathrm{Ce}_{11} \mathrm{O}_{20}$ phase. The fluorite, bixbyite, rhombohedral and triclinic phases of ceria are abbreviated as $\mathrm{fl}$, bix, rh and tri, respectively, in panel $\mathrm{B}$ and $\mathrm{D}$. The structure refinement plots of the XRD patterns in panel B and D are shown in Fig. S3 and S4 in the ESI, $\dagger$ respectively.

in $\mathrm{H}_{2}$ exhibits an analogous thermal expansion mediated increase with temperature only up to $800 \mathrm{~K}$, before showing a rapid additional increase with further rising temperature, which indicates the extraction of lattice oxygen from the samples. On the other hand, during cooling in $\mathrm{H}_{2}$ the pseudocubic lattice parameter of the bixbyite phases, which is obtained by dividing the lattice parameter of parent bixbyite by 2, shows a linear decrease with temperature down to 810 $\mathrm{K}$ and $715 \mathrm{~K}$ for pure $\mathrm{CeO}_{2}$ and SDC15, respectively, then it apparently stops to contract, followed by a second decrease below $580 \mathrm{~K}$. Moreover, the pseudo-cubic lattice parameters of the formed $\mathrm{rh}-\mathrm{Ce}_{7} \mathrm{O}_{12}$ and tri- $\mathrm{Ce}_{11} \mathrm{O}_{20}$ phases, which are calculated from the volume of the rhombohedral and triclinic cells, display a linear decrease with temperature as soon as 

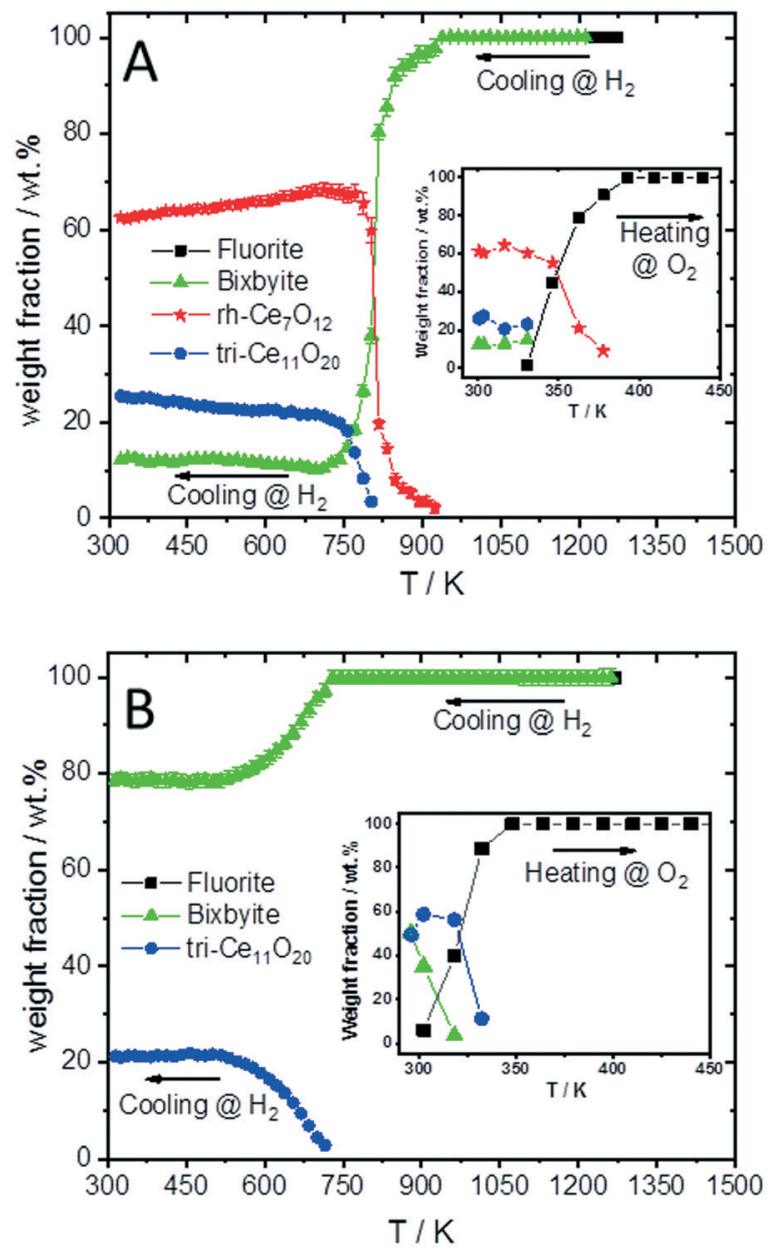

Fig. 2 Temperature evolution of weight fraction of different phases formed during cooling of $\mathrm{CeO}_{2}$ (A) and SDC15 (B) specimens from $1273 \mathrm{~K}$ in $\mathrm{H}_{2}$ atmosphere. The insets in figure $A$ and $B$ show the weight fraction during the re-oxidation of $\mathrm{CeO}_{2}$ and SDC15, respectively, in flowing $\mathrm{O}_{2}$.

they are formed. The pseudo-cubic lattice parameters can be simply calculated from the unit cell volume of the triclinic and rhombohedral phases. For example, $r$ h- $\mathrm{Ce}_{7} \mathrm{O}_{12}$ has 3 unit formulae per unit cell, while fluorite has 4 unit formulae. This means that each unit cell of $\mathrm{Ce}_{7} \mathrm{O}_{12}$ has $3 \times 7=21 \mathrm{Ce}$, while fluorite has $4 \mathrm{Ce}$, indicating that the pseudo-cubic cell of rh- $-\mathrm{Ce}_{7} \mathrm{O}_{12}$ equals the volume of the rh- $\mathrm{Ce}_{7} \mathrm{O}_{12}$ cell times $4 / 21$. Then the lattice parameter can be calculated from the cube root of the volume of the obtained pseudo-cubic cell. These results can be explained by the change in oxygen vacancy concentrations and the concomitant change of $\mathrm{Ce}^{3+} /$ $\mathrm{Ce}^{4+}$ ratios (for charge compensation) in the samples during the heating/cooling in $\mathrm{H}_{2}$ atmosphere.

In order to confirm these results, the amount of oxygen vacancies $\delta$ and mole fraction $y$ of $\mathrm{Ce}^{3+}$ in all phases at given temperature $T$ are determined by using the well-known relationship between the amount of oxygen (i.e. $2-\delta$ ) in $\mathrm{CeO}_{2-\delta}$ and pseudo-cubic lattice parameter $a$ experimentally derived by Ray $e t a l$. (henceforth this approach is called model 1). ${ }^{20}$ The increase in the lattice parameters of fluorite and bixbyite phases due to thermal expansion was determined by the linear fitting of experimental data for the samples heated in $\mathrm{O}_{2}$ atmosphere and extrapolation to higher temperatures. As the pseudo-cubic lattice parameter of rh- $\mathrm{Ce}_{7} \mathrm{O}_{12}$ and tri-Ce ${ }_{11} \mathrm{O}_{20}$ phases show an almost linear dependence of temperature during cooling in $\mathrm{H}_{2}$, their thermal expansions were determined from these data. The calculated lattice parameter values were subtracted from the experimental values before calculating the amount of oxygen vacancies $\delta$ and the mole fraction $y$ of $\mathrm{Ce}^{3+}$.

As shown in Fig. 3C and D, the amount of the oxygen vacancies (derived by model 1) in the fluorite phases of both samples heated in $\mathrm{H}_{2}$ from room temperature up to $800 \mathrm{~K}$ does not change, which suggests that the increase in the lattice parameters in this temperature range is due to the thermal expansion effect. Above $800 \mathrm{~K}$, lattice oxygen release becomes predominant resulting in the generation of more oxygen vacancies and induces the valence decrease of $\mathrm{Ce}^{4+}$ ions for charge compensation. Thus, the lattice parameter of the fluorite structures sharply increases due to the combined thermal and chemical expansion.

The increased oxygen nonstoichiometry $\delta$ (derived by model 1) after heating both samples in $\mathrm{H}_{2}$ to $1273 \mathrm{~K}(\delta \approx$ 0.28) resulted in the transformation of the fluorite phase into oxygen-deficient bixbyite structures. The determined formulae are $\mathrm{Ce}_{0.58}{ }^{3+} \mathrm{Ce}_{0.42}{ }^{4+} \mathrm{O}_{1.71}$ (derived from pure $\mathrm{CeO}_{2}$ ) and $\mathrm{Sm}_{0.15}{ }^{3+} \mathrm{Ce}_{0.39}{ }^{3+} \mathrm{Ce}_{0.46}{ }^{4+} \mathrm{O}_{1.73}$ (derived from SDC15), which form during the cooling routine in $\mathrm{H}_{2}$ at $1228 \mathrm{~K}$ and $1263 \mathrm{~K}$, respectively. Below these temperatures and down to $810 \mathrm{~K}$ and $715 \mathrm{~K}$ for pure $\mathrm{CeO}_{2}$ and SDC15, respectively, no more oxygen vacancies are generated in the bixbyite phases, thus, their lattice parameters decrease linearly with temperature due to the thermal contraction effect. This result is further confirmed by the partial transformation of the bixbyite phase into rhombohedral rh- $\mathrm{Ce}_{7} \mathrm{O}_{12}$ (i.e. $\mathrm{Ce}_{0.58}{ }^{3+} \mathrm{Ce}_{0.42}{ }^{4+} \mathrm{O}_{1.71}$ ) at 924 $\mathrm{K}$ in pure $\mathrm{CeO}_{2}$, whereby both phases have the same amount of oxygen vacancies. This agrees also with a previous work ${ }^{18}$ showing that the difference in oxygen nonstoichiometry between bixbyite and $\mathrm{rh}-\mathrm{Ce}_{7} \mathrm{O}_{12}$ is very small and the most essential difference between the two structures is the relative orientations of oxygen anions and oxygen vacancies along the [111]-direction. On the other hand, a rh- $\mathrm{Ce}_{7} \mathrm{O}_{12}$ type phase is not observed in the SDC15 specimen at any temperature, which indicates that Sm doping leads to the stabilization of the bixbyite phase over the rhombohedral one at this particular oxygen vacancy concentration. In the temperature ranges 810-580 K and 715-580 K for pure $\mathrm{CeO}_{2}$ and SDC15, respectively, the amount of oxygen vacancies and $\mathrm{Ce}^{3+}$ ions increase again in the bixbyite phases, leading to an increase in the lattice parameters that compensates the decrease due to the thermal contraction effect. Therefore, the lattice parameters of the bixbyite phases stay relatively constant in these temperature ranges. As shown in Fig. 2 and 3C-F, this increase in the amount of oxygen vacancies and $\mathrm{Ce}^{3+}$ ions in the bixbyite phases is accompanied by the formation of the tri$\mathrm{Ce}_{11} \mathrm{O}_{20}$ phase (i.e. $\mathrm{Ce}_{0.48}{ }^{3+} \mathrm{Ce}_{0.52}{ }^{4+} \mathrm{O}_{1.76}$ and $\mathrm{Sm}_{0.15}{ }^{3+} \mathrm{Ce}_{0.31}{ }^{3+}$ - 

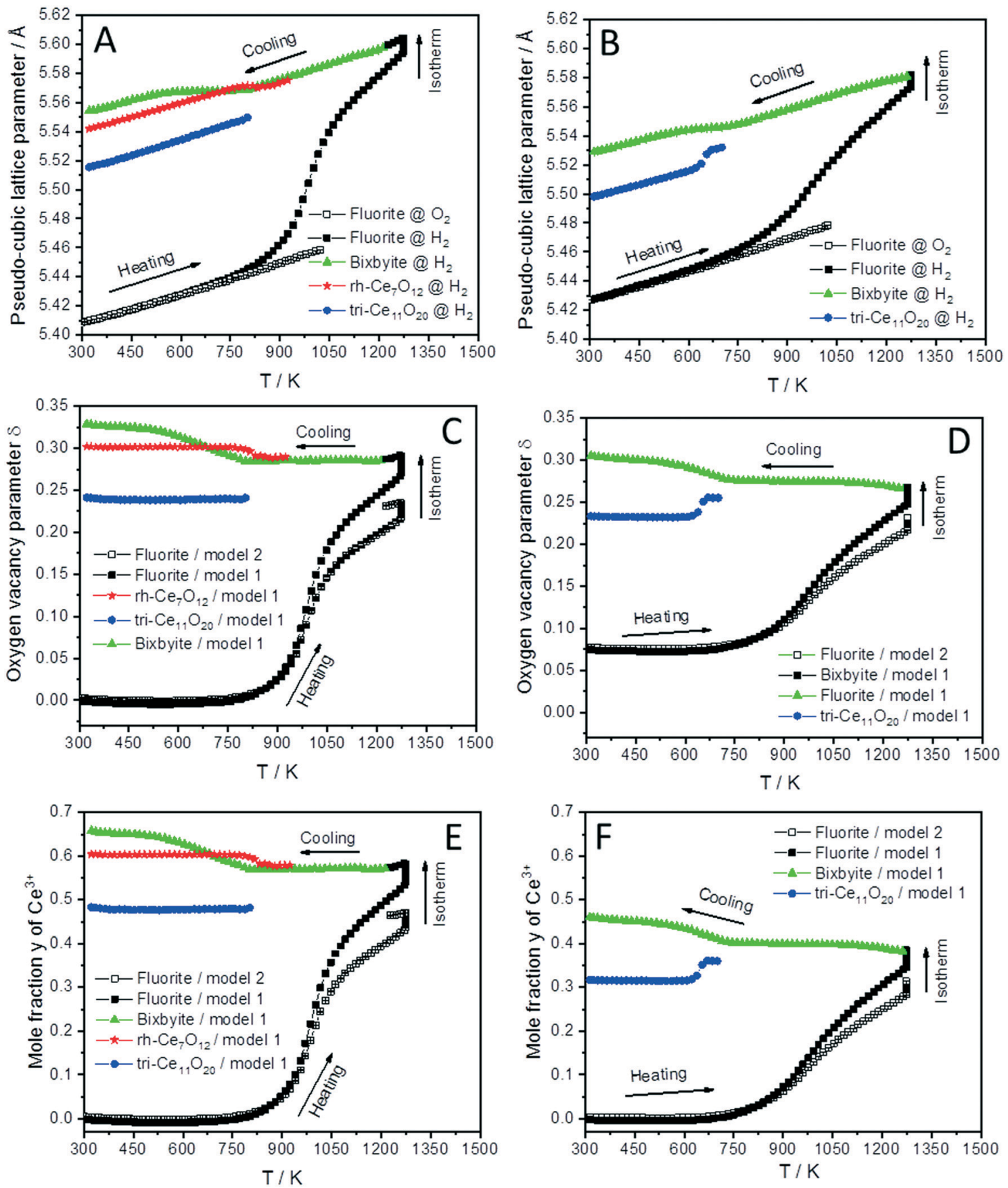

Fig. 3 Temperature evolution of the pseudo-cubic lattice parameters ( $A$ and $B$ ), the oxygen vacancy parameter $\delta(C$ and $D)$ and mole fraction $y$ of $\mathrm{Ce}^{3+}\left(\mathrm{E}\right.$ and $\mathrm{F}$ ) of different phases formed during cooling of $\mathrm{CeO}_{2}(\mathrm{~A}, \mathrm{C}$ and $\mathrm{E})$ and $\mathrm{SDC} 15\left(\mathrm{~B}, \mathrm{D}\right.$ and $\mathrm{F}$ ) specimens from $1273 \mathrm{~K}$ in $\mathrm{H}_{2}$ atmospheres. The oxygen vacancy parameter and mole fraction $y$ of $\mathrm{Ce}^{3+}$ were calculated from the relationship between the amount of oxygen (i.e. $2-\delta$ ) in $\mathrm{CeO}_{2-\delta}$ and the pseudo-cubic lattice parameters a (termed "model 1"), as well as using eqn (2) (termed "model 2").

$\left.\mathrm{Ce}_{0.54}{ }^{4+} \mathrm{O}_{1.77}\right)$ at 800 and $715 \mathrm{~K}$ for pure $\mathrm{CeO}_{2}$ and $\mathrm{SDC} 15$, respectively. The bixbyite phases in the pure ceria and SDC15 samples (at RT after $\mathrm{H}_{2}$ treatment) exhibit the chemical compositions of $\mathrm{Ce}_{0.66}{ }^{3+} \mathrm{Ce}_{0.34}{ }^{4+} \mathrm{O}_{1.67}$ and $\mathrm{Sm}_{0.15}{ }^{3+} \mathrm{Ce}_{0.47}{ }^{3+}$ $\mathrm{Ce}_{0.38}{ }^{4+} \mathrm{O}_{1.69}$, respectively. In comparison to the bixbyite phases formed at higher temperatures (i.e. $T>800 \mathrm{~K}$ ) the RT bixbyite phases of both samples have a slightly higher oxygen vacancy concentration. These results suggest the for- mation of tri-Ce ${ }_{11} \mathrm{O}_{20}$ from the high-temperature bixbyite phase or $r h-\mathrm{Ce}_{7} \mathrm{O}_{12}$ according to the following chemical reactions:

$$
\begin{aligned}
& \text { b-/rh- }-\mathrm{Ce}_{0.58}{ }^{3+} \mathrm{Ce}_{0.42}{ }^{4+} \mathrm{O}_{1.71} \rightarrow \operatorname{tri}^{3+} \mathrm{Ce}_{0.48}{ }^{3+} \mathrm{Ce}_{0.52}{ }^{4+} \mathrm{O}_{1.76} \\
& \quad+\text { b-Ce }{ }_{0.66}{ }^{4+} \mathrm{Ce}_{0.34} \mathrm{O}_{1.67}
\end{aligned}
$$

for the pure $\mathrm{CeO}_{2}$ sample and 


$$
\begin{gathered}
\text { b- }-\mathrm{Sm}_{0.15}{ }^{3+} \mathrm{Ce}_{0.39}{ }^{3+} \mathrm{Ce}_{0.46}{ }^{4+} \mathrm{O}_{1.73} \rightarrow \text { tri-Sm }_{0.15}{ }^{3+} \mathrm{Ce}_{0.31}{ }^{3+} \mathrm{Ce}_{0.54}{ }^{4+} \mathrm{O}_{1.77} \\
+ \text { b-Sm }{ }_{0.15}{ }^{3+} \mathrm{Ce}_{0.47}{ }^{3+} \mathrm{Ce}_{0.38}{ }^{4+} \mathrm{O}_{1.69}
\end{gathered}
$$

for the SDC15 sample.

Additionally, despite of the fact that the fluorite structure of $\mathrm{Sm}_{0.15} \mathrm{Ce}_{0.85} \mathrm{O}_{1.926}$ has a larger lattice parameter than that of $\mathrm{CeO}_{2}$, the tri-Sm $\mathrm{Sm}_{0.15}{ }^{3+} \mathrm{Ce}_{0.31}{ }^{3+} \mathrm{Ce}_{0.54}{ }^{4+} \mathrm{O}_{1.77}$ phase possesses a smaller lattice parameter than tri-Ce $e_{0.48}{ }^{3+} \mathrm{Ce}_{0.52}{ }^{4+} \mathrm{O}_{1.76}$, which agrees with the order of the ion sizes, $\mathrm{Ce}^{3+}>\mathrm{Sm}^{3+}>\mathrm{Ce}^{4+}$. Below $580 \mathrm{~K}$, no significant changes in the oxygen vacancies are observed in all phases, therefore, their lattice parameters decrease linearly with temperature due to the thermal contraction effect. In consequence, the weight fractions of different phases do not change significantly also in both samples below this temperature ( $c f$. Fig. 2). Furthermore, it is noteworthy that the oxygen contents determined in bixbyite and rh- $\mathrm{Ce}_{7} \mathrm{O}_{12}$ phases observed in both samples are in good agreement with previous reports on pure $\mathrm{CeO}_{2} \cdot{ }^{18,20,45}$ In contrast, the amounts of oxygen in the tri- $\mathrm{Ce}_{11} \mathrm{O}_{20}$ phases (i.e. 1.761.77) are found to be slightly lower than those reported in the literature (i.e. 1.80-1.832). ${ }^{18,20,45}$ Previous single-crystal neutron scattering measurements showed that $\mathrm{CeO}_{1.765}$ is preferentially crystallized in the rhombohedral structure. ${ }^{46}$ However, all attempts to refine the diffraction pattern of this phase in the rhombohedral structure were unsuccessful, and only using the triclinic structure gave better fitting between the observed and calculated profiles. Interestingly, the oxygen contents determined in the bixbyite and triclinic phases formed in the pure $\mathrm{CeO}_{2}$ sample are found to be very close to those of same phases formed in the SDC15 sample, which indicates that the stabilization of bixbyite and triclinic phases depends on the amount of oxygen vacancies, regardless of Sm doping.

In the next step, the obtained mole fraction $y$ of $\mathrm{Ce}^{3+}$ and the oxygen vacancies parameter $\delta$ in the reduced fluorite phases at a given temperature $T$ are calculated by using the relationship $^{23}$ (which we refer to as model 2):

$$
a_{\text {reduced }}-a_{\text {unreduced }}=\frac{4}{\sqrt{3}}\left[r_{\mathrm{Ce}^{3+}}-r_{\mathrm{Ce}^{4+}}-0.25 r_{\mathrm{O}}+0.25 r_{v_{\mathrm{O}}}\right] y
$$

where $a_{\text {reduced }}$ and $a_{\text {unreduced }}$ are the lattice parameters of reduced (i.e. heated in $\mathrm{H}_{2}$ ) and unreduced fluorite phases (i.e. heated in $\mathrm{O}_{2}$ ), respectively, at the same temperature. $r_{\mathrm{Ce}^{3+}}$ is the ionic radius of $\mathrm{Ce}^{3+}(1.143 \AA)$ in a 8-fold coordination. ${ }^{43}$ As our recent work showed that the $\mathrm{Sm} / \mathrm{Ce}$ ratio as well as oxidation state of $\mathrm{Sm}^{3+}$ are not changed during the reduction process in $\mathrm{H}_{2}$, the mole fraction $x$ of Sm in the reduced fluorite phases (i.e. $\mathrm{Sm}_{x} \mathrm{Ce}_{y}^{\mathrm{III}} \mathrm{Ce}_{1-x+y} \mathrm{O}_{2-\delta}$ ) is assumed to be the same as in the unreduced phases (i.e. $\left.\mathrm{Sm}_{x} \mathrm{Ce}_{1-x} \mathrm{O}_{2-\delta}\right) \cdot{ }^{23}$ As shown in Fig. 3C-F, the difference between the values of the mole fraction $y$ of $\mathrm{Ce}^{3+}$ and oxygen vacancies parameter $\delta$ calculated from both models is negligible below $1030 \mathrm{~K}$ (during the heating phase) and becomes remarkable at higher temperatures, which can be explained by large displacement of cations and anions as well as the disordered vacancy distribu- tion at high temperature. Since eqn (2) is derived for the ordered fluorite structure, any slight disorder in the structure could result in a significant error in the calculated values of oxygen vacancies or $\mathrm{Ce}^{3+}$ content.

Finally, the stabilities of the bixbyite, $r \mathrm{rh}_{7} \mathrm{O}_{12}$ and tri$\mathrm{Ce}_{11} \mathrm{O}_{20}$ phases in the recovered samples at RT after $\mathrm{H}_{2}$ prereduction were studied by re-heating of the recovered samples in a $\mathrm{O}_{2}$ atmosphere. As shown in Fig. 4, the bixbyite and tri- $\mathrm{Ce}_{11} \mathrm{O}_{20}$ phases in both samples are transformed to a fluorite phase at very low temperature (i.e. $T<330 \mathrm{~K}$ ), while the rh- $\mathrm{Ce}_{7} \mathrm{O}_{12}$ phase in the pure $\mathrm{CeO}_{2}$ sample disappears at slightly higher temperature (i.e. $377 \mathrm{~K}$ ). These results indicate that these oxygen deficient phases are metastable and can be easily oxidized to the stoichiometric fluorite phase at low temperature.

The sequence of phase transitions in ceria induced by thermal treatment and oxygen non-stoichiometry can be explained as follows. The thermal diffusion and incorporation of hydrogen into $\mathrm{CeO}_{2}$ lattice under hydrogen atmosphere above $900 \mathrm{~K}$ results in the formation of oxygen vacancies due to the release of water molecules, which in turn leads to the oxygen deficient fluorite polymorph with a fully disordered network of oxygen vacancies. In contrast, the bixbyite and rhombohedral phases show an ordering of oxygen vacancies. ${ }^{18,47}$ As the latter is strongly influenced by temperature and stress, during the cooling the disordered oxygen vacancies in the fluorite phase start to be ordered leading to the transformation of disordered fluorite phase into the ordered bixbyite phase and rhombohedral rh- $\mathrm{Ce}_{7} \mathrm{O}_{12}$, whereby all three phases have almost the same amount of oxygen vacancies (Fig. 3) and differ only in their ordering. As the diffusion and incorporation of hydrogen into bixbyite lattice is hindered below $800 \mathrm{~K}$, the reduced b-Ce $\mathrm{Ce}_{0.58}{ }^{3+} \mathrm{Ce}_{0.42}{ }^{4+} \mathrm{O}_{1.71}$ particles becomes unstable. As a result, the b-Ce $\mathrm{Ce}_{0.58}{ }^{3+} \mathrm{Ce}_{0.42}{ }^{4+} \mathrm{O}_{1.71}$ is oxidized into tri- $\mathrm{Ce}_{11} \mathrm{O}_{20}$ (i.e. tri-Ce $\mathrm{Ce}_{0.48}{ }^{3+} \mathrm{Ce}_{0.52}{ }^{4+} \mathrm{O}_{1.76}$ ) in the bulk of the particle by accepting oxygen from the outer surface region and forming new bixbyite phase with more oxygen vacancies (i.e. b-Ce $\mathrm{Ce}_{0.66}{ }^{3+} \mathrm{Ce}_{0.34}{ }^{4+} \mathrm{O}_{1.67}$ ). Our finding is in line with a recently proposed mechanism for the transformation of oxygen-deficient fluorite $\mathrm{CeO}_{2-x}$ into tri- $\mathrm{Ce}_{11} \mathrm{O}_{20}$ and stochiometric $\mathrm{CeO}_{2}$ below $773 \mathrm{~K}$ during cooling after heating the sample for 20 hours in hydrogen $\left(3 \% \mathrm{H}_{2}\right.$ in $\left.\mathrm{N}_{2}\right)$ atmosphere. ${ }^{48}$

Revisiting the in situ XRD experiments in brief, and to refocus on the initial research question whether $\mathrm{CeH}_{x}$ cerium hydride phases can be detected during the hydrogen treatments as reported previously, ${ }^{27}$ an intermittent summarizing statement will reveal that under our specific experimental circumstances neither for pure nor for acceptor-doped $\mathrm{CeO}_{2}$ any sign of such a crystalline cerium hydride phase was detected. All patterns can satisfactorily be explained by the aforementioned structures in the $\mathrm{Ce}-\mathrm{O}$ phase diagram, which strongly contradicts a recent study suggesting the presence of an "oxygen-free" $\mathrm{CeH}_{x}$ phase by evaluation of inelastic neutron scattering data. ${ }^{27}$ Our previous results, ${ }^{23}$ among other studies, nevertheless clearly prove the presence of dissolved hydrogen e.g. in the defective $\mathrm{CeO}_{2-x}$ structure (starting from 

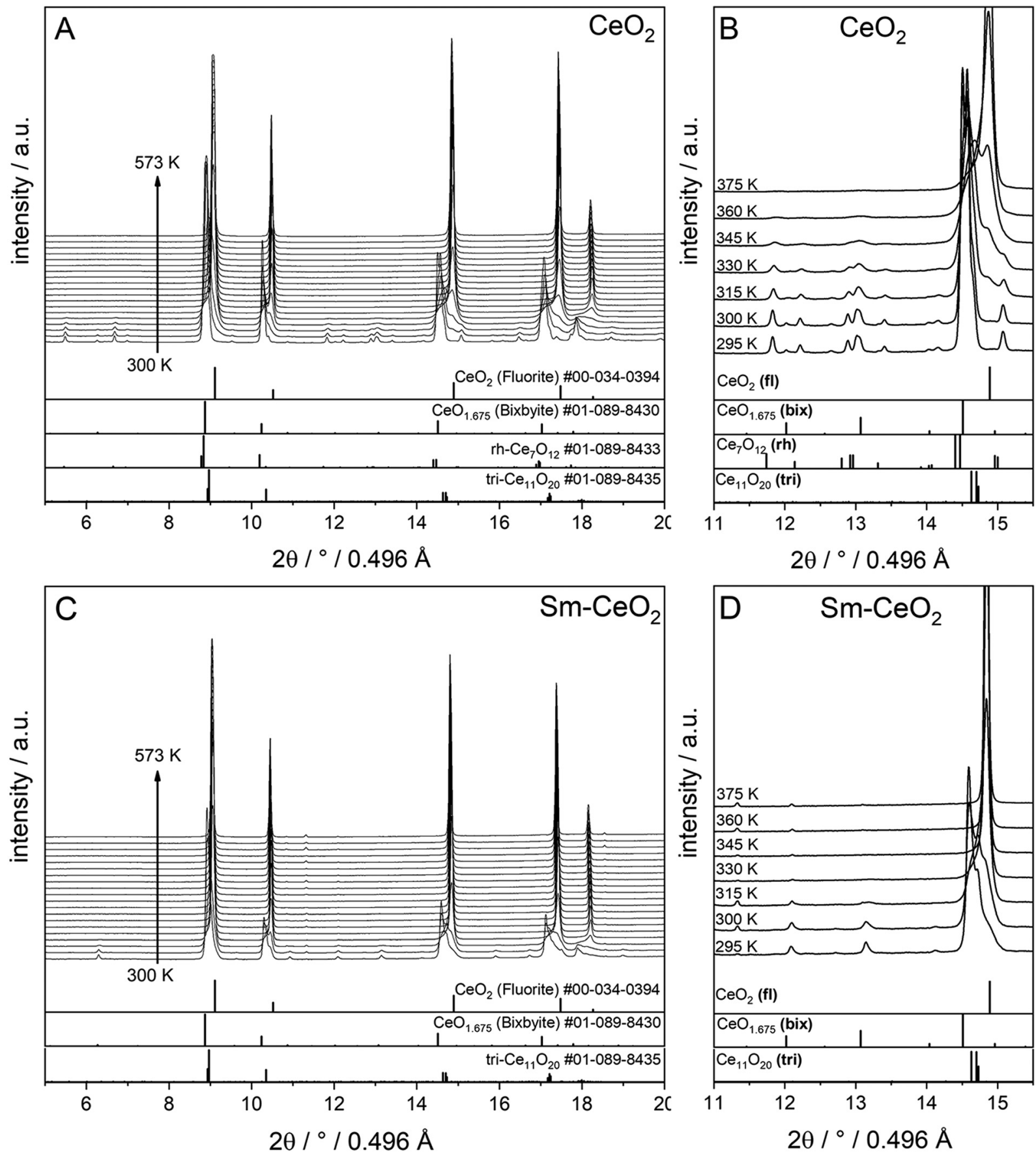

Fig. 4 In situ XRD patterns $\left(\lambda=0.4957 \AA\right.$ ) collected during re-oxidation of $\mathrm{CeO}_{2}(\mathrm{~A}$ and $\mathrm{B})$ and $\mathrm{SDC} 15$ (C and $\left.\mathrm{D}\right)$ specimens in flowing $\mathrm{O}_{2}$ atmospheres directly after $\mathrm{H}_{2}$ pre-reduction. Panels $A$ and $\mathrm{C}$ show in situ XRD patterns in a broad $2 \Theta$ range and in a temperature interval between 300 $\mathrm{K}$ and $573 \mathrm{~K}$. Panels $\mathrm{B}$ and $\mathrm{D}$ focus on the some temperature regions to allow for closer analysis in a narrower $2 \Theta$ window. The calculated diffraction patterns of the fluorite $\mathrm{CeO}_{2}$, bixbyite $\mathrm{CeO}_{1.675}, \mathrm{rh}-\mathrm{Ce}_{7} \mathrm{O}_{12}$ and tri- $\mathrm{Ce}_{11} \mathrm{O}_{20}$ structures are shown at the bottom. The fluorite, bixbyite, rhombohedral and triclinic phases of ceria are abbreviated as fl, bix, rh and tri, respectively, in panel $B$ and $D$. The structure refinement plots of the XRD patterns in panel $B$ and $D$ are shown in the ESI $\dagger$ as Fig. S5 and S6, respectively.

pure $\mathrm{CeO}_{2}$ as well as Gd- and Sm-doped phases), but the presence of dissolved hydrogen did, at least in our case, not induce hitherto entirely unknown or crystallographically unclear phase changes. The same holds for recently reported hydrogen-containing, but allegedly vacancy-free, $\mathrm{H}_{x} \mathrm{CeO}_{2}$ ceria oxyhydroxide phases, ${ }^{36}$ which were also not detected during our in situ experiments.
In order to shed light on the eventual bonding of hydrogen within the reduced $\mathrm{CeO}_{2-x}$ structures, we additionally performed ex situ ${ }^{1} \mathrm{H}-\mathrm{NMR}$ experiments on hydrogen-treated pure and $\mathrm{Sm}$-doped $\mathrm{CeO}_{2}$ after treating the samples at 1173 $\mathrm{K}$ in 1 bar of flowing/dry $\mathrm{H}_{2}$. Solid state ${ }^{1} \mathrm{H}-\mathrm{NMR}$ spectroscopy is a well-established tool for the detection of various hydrogen species bound by ceria. $^{24,31,32,49}$ Fig. 5 shows these 
spectra in a comparative fashion before and after the hydrogen treatments.

At first glance, the features of, and the differences between the spectra of the oxidized and $\mathrm{H}_{2}$-reduced samples appear very similar. For both samples, the oxidized state is characterized by a distinct double peak with, however, variable intensity at higher chemical shifts (around $5 \mathrm{ppm}$ ). This peak is subsequently lost during the reduction treatment of both materials and only a pronounced and rather broad proton resonance at $\sim 2 \mathrm{ppm}$ remains. A similar behaviour was observed for pure $\mathrm{CeO}_{2}$ by Al-Madfaa et al. who reduced $\mathrm{CeO}_{2}$ by $\mathrm{H}_{2}$ and then adsorbed $\mathrm{H}_{2} \mathrm{O}$, so generating $\mathrm{OH}$ groups which could be detected by ${ }^{1} \mathrm{H}$ MAS NMR. ${ }^{50}$

Adapting an interpretation of similar spectra collected on commercial and nanoarchitectured ceria materials, ${ }^{47}$ the vanishing peak can be associated with physisorbed water layers. In contrast, the persisting peak can be associated with very stable $\mathrm{OH}$ groups adsorbed on specific crystallite sites. Interestingly, this peak exhibits almost exactly the same appearance for both the pure and the undoped ceria sample. Hence, we can conclude that this specific adsorption is not influenced by acceptor doping. Most importantly, no distinct magnetic ${ }^{1} \mathrm{H}$ resonances of any cerium hydride species which are expected to show up at lower fields compared to $\mathrm{OH}$ (ref. 51) - are detectable.

As the 2 ppm signal of pure $\mathrm{CeO}_{2}$ (air-calcined sample) is investigated, a sharp spike can be found at $1.12 \mathrm{ppm}$ which disappears if the sample is heated in $\mathrm{H}_{2}$ at elevated temperatures. This particular feature can be assigned to highly mobile hydrogen $^{52,53}$ and is completely missing on air-calcined SDC15. In general the $\mathrm{OH}$ signal decreases slightly as hydroxyl groups are removed from the sample by reacting with $\mathrm{H}_{2}$. In summary, the NMR experiments do not bear surprising results in terms of new $\mathrm{OH}$ species, but equally, no hidden hydride species are observed either - at least not under the chosen experimental conditions.

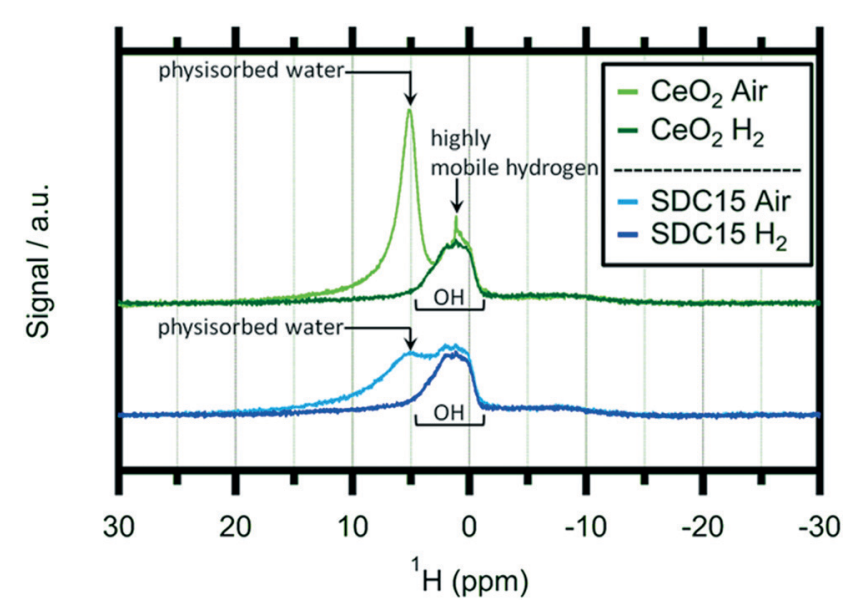

Fig. $5{ }^{1} \mathrm{H}$-MAS NMR spectra of pure $\mathrm{CeO}_{2}$ (greenish traces) and $\mathrm{Sm}$ doped $\mathrm{CeO}_{2}$ (SDC15) (bluish traces) collected after treatment in air at $1273 \mathrm{~K}$ and after a reductive heating-cooling cycle up to $1173 \mathrm{~K}$ in 1 bar hydrogen. Important signals have been marked.

\section{Conclusions}

Through exploitation of in situ X-ray diffraction experiments under strongly reducing conditions we have shown that the formation of cerium hydride phases under the chosen experimental conditions can be excluded. Rather, a succession of different phase transformations in the $\mathrm{Ce}-\mathrm{O}$ phase diagram has been observed, with a strong dependence on the $\mathbf{M}^{3+}$ doping level of $\mathrm{CeO}_{2}$. The chosen doping level of $\mathrm{Sm}-\mathrm{CeO}_{2}$ leads to particular stabilization of a reduced bixbyite b-CeO $\mathrm{C}_{2-\delta}$ phase, which inhibits the intermediate formation of rhombohedral $\mathrm{Ce}_{7} \mathrm{O}_{12}$ as observed on pure $\mathrm{CeO}_{2}$. The final structural stage of both ceria materials is a reduced triclinic $\mathrm{Ce}_{11} \mathrm{O}_{20}$ phase. On the basis of our experiments, and also under observance of the fact that previous quantitative ex situ experiments have given clear evidence that dissolved hydrogen exists within the reduced ceria structures after the chosen hydrogen treatments, this hydrogen was not detectable in the form of a $\mathrm{CeH}_{x}$ cerium hydride compound. As such we conclude that crystalline hydride phases of cerium can hardly play a catalytic role in e.g. hydrogenation reactions or are substantially formed in other $\mathrm{H}_{2}$-containing gas environments.

\section{Conflicts of interest}

There are no conflicts to declare.

\section{Acknowledgements}

M. Grünbacher and S. Penner acknowledge funding from the Austrian Science Fund (FWF) within the SFB project F4503N16 "Functional Oxide Surfaces and Interfaces". The work was performed within the framework of the research platform "Materials- and Nanoscience" and the special PhD program "Reactivity and Catalysis" at the University of Innsbruck. L. Schlicker appreciates the ALS for supporting his work with a doctoral fellowship. The authors further thank the Advanced Light Source (which is supported by the Director, Office of Science, Office of Basic Energy Sciences, of the U.S. Department of Energy under Contract No. DE-AC02-05CH11231), where in situ XRD measurements were conducted at beamline 12.2.2 in the framework of the AP program ALS-08865.

\section{References}

1 A. Trovarelli, Chem. Rev., 1996, 38, 439-520.

2 A. F. Diwell, R. R. Rajaram, H. A. Shaw and T. J. Treux, The role of ceria in three-way catalysts, in Catalysis Automotive Pollution Control, Elsevier, Amsterdam, 71st edn, 1991.

3 P. Bera, K. C. Patil and M. S. Hegde, Phys. Chem. Chem. Phys., 2000, 2, 3715-3719.

4 H. C. Yao and Y. F. Yu Yao, J. Catal., 1984, 86, 254-265.

5 L. Kundakovic and M. Flytzani-Stephanopoulos, J. Catal., 1998, 179, 203-221.

6 A. I. Boronin, E. M. Slavinskaya, I. G. Danilova, R. V. Gulyaev, Y. I. Amosov, P. A. Kuznetsov, I. A. Polukhina, S. V. 
Koscheev, V. I. Zaikovskii and A. S. Noskov, Catal. Today, 2009, 144, 201-211.

7 Z. Wu, H. Zhu, Z. Qin, H. Wang, J. Ding, L. Huang and J. Wang, Fuel, 2013, 104, 41-45.

8 N. Bion, F. Epron, M. Moreno, F. Marino and D. Duprez, Top. Catal., 2008, 51, 76-88.

9 R. J. Gorte and S. Zhao, Catal. Today, 2005, 104, 18-24.

10 D. R. Mullins, S. D. Senanayake and T.-L. Chen, J. Phys. Chem. C, 2010, 114, 17112-17119.

11 M. I. Zaki and N. Sheppard, J. Catal., 1983, 80, 114-122.

12 S. Imamura, D. Uchihori, K. Utani and T. Ito, Catal. Lett., 1994, 24, 377-384.

13 K. Werner, X. Weng, F. Calaza, M. Sterrer, T. Kropp, J. Paier, J. Sauer, M. Wilde, K. Fukutani, S. Shaikhutdinov and H.-J. Freund, J. Am. Chem. Soc., 2017, 139, 17608-17616.

14 J. W. Fergus, J. Power Sources, 2006, 162, 30-40.

15 S. Yong, W. Shijie and S. Pei-Chen, Sci. Rep., 2016, 6, 1-9.

16 E. Rebollo, C. Mortalo, S. Escolastico, S. Boldrini, S. Barison, J. M. Serra and M. Fabrizio, Energy Environ. Sci., 2015, 8, 3675-3686.

17 B. F. Hoskins and R. L. Martin, Aust. J. Chem., 1995, 48, 709-739.

18 E. A. Kümmerle and G. Heger, J. Solid State Chem., 1999, 147, 485-500.

19 S. P. Ray and D. E. Cox, J. Solid State Chem., 1975, 15, 333-343.

20 S. P. Ray, A. S. Nowick and D. E. Cox, J. Solid State Chem., 1975, 15, 344-351.

21 V. Perrichon, A. Laachir, G. Bergeret, R. Frety and L. Tournayan, J. Chem. Soc., Faraday Trans., 1994, 90, 773-781.

22 J. Höcker, J.-O. Krisponeit, T. Schmidt, J. Falta and J. I. Flege, Nanoscale, 2017, 9, 9352-9358.

23 M. Grünbacher, L. Schlicker, M. F. Bekheet, A. Gurlo, B. Klötzer and S. Penner, Phys. Chem. Chem. Phys., 2018, 20, 22099-22113.

24 J. L. G. Fierro, J. Soria, J. Sanz and J. M. Rojo, J. Solid State Chem., 1987, 66, 154-162.

25 S. M. Schimming, G. S. Foo, O. D. La Mont, A. K. Rogers, M. M. Yung, A. D. D'Amico and C. Sievers, J. Catal., 2015, 329, 335-347.

26 A. Laachir, V. Perrichon, A. Badri, J. Lamotte, E. Catherine, J.-C. Lavalley, J. El Fallah, L. Hilaire, F. Le Normand, E. Quemere, G. N. Sauvion and O. Touret, J. Chem. Soc., Faraday Trans., 1991, 87, 1601-1609.

27 Z. Wu, Y. Cheng, F. Tao, L. Daemen, G. S. Foo, L. Nguyen, X. Zhang, A. Beste and A. J. Ramirez-Cuesta, J. Am. Chem. Soc., 2017, 139, 9721-9727.

28 L. A. Bruce, M. Hoang, A. E. Hughes and T. W. Turney, Appl. Catal., A, 1996, 134, 351-362.

29 K. Sohlberg, S. T. Pantelides and S. J. Pennycook, J. Am. Chem. Soc., 2001, 123, 6609-6611.

30 X.-P. Wu, X.-Q. Gong and G. Lu, Phys. Chem. Chem. Phys., 2015, 17, 3544-3549.
31 D. M. Lyons, J. P. McGrath and M. A. Morris, J. Phys. Chem. $B, 2003,107,4607-4617$.

32 J. M. Rojo, J. Sanz, J. A. Soria and J. L. G. Fiero, Z. Phys. Chem., 1987, 152, 149-158.

33 L. Jalowiecki-Duhamel, S. Debeusscher, H. Zarrou, A. D'Huysser, H. Jobic and E. Payen, Catal. Today, 2008, 138, 266-271.

34 L. Jalowiecki-Duhamel, Int. J. Hydrogen Energy, 2006, 31, 191-195.

35 L. Jalowiecki-Duhamel, J. Carpentier and A. Ponchel, Int. J. Hydrogen Energy, 2007, 32, 2439-2444.

36 T. Matsukawa, A. Hoshikawa, E. Niwa, M. Yashima and T. Ishigaki, CrystEngComm, 2018, 20, 155-158.

37 N. Sakai, K. Yamaji, T. Horita, H. Yokokawa, Y. Hirata, S. Sameshima, Y. Nigara and J. Mizusaki, Solid State Ionics, 1999, 125, 325-331.

38 A. Doran, L. Schlicker, C. M. Beavers, S. Bhat, M. F. Bekheet and A. Gurlo, Rev. Sci. Instrum., 2017, 88, 13903.

39 L. Schlicker, A. Doran, P. Schneppmüller, A. Gili, M. Czasny, S. Penner and A. Gurlo, Rev. Sci. Instrum., 2018, 89, 33904.

40 J. Rodriguez-Carvajal, IUCrJ, 2001, 26, 12-19.

41 L. W. Finger, D. E. Cox and A. P. Jephcoat, J. Appl. Crystallogr., 1994, 27, 892-900.

42 G. Brauer and H. Gradinger, Z. Anorg. Allg. Chem., 1954, 277, 89-95.

43 R. D. Shannon and C. T. Prewitt, Acta Crystallogr., Sect. B: Struct. Crystallogr. Cryst. Chem., 1969, 25, 925-946.

44 S. J. Hong and A. V. Virkar, J. Am. Ceram. Soc., 1995, 78, 433-439.

45 P. Knappe and L. Eyring, J. Solid State Chem., 1985, 58, 312-324.

46 E. A. Kümmerle, F. Güthoff, W. Schweika and G. Heger, J. Solid State Chem., 2000, 153, 218-300.

47 R. J. Gaboriaud, F. Paumier and B. Lacroix, Thin Solid Films, 2016, 601, 84-88.

48 T. Matsukawa, A. Hoshikawa and T. Ishigaki, CrystEngComm, 2018, 20, 4359-4363.

49 L. Gill, A. Beste, B. Chen, M. Li, A. K. P. Mann, S. H. Overbury and E. W. Hagaman, J. Phys. Chem. C, 2017, 13, 7450-7465.

50 H. A. Al-Madfaa, M. M. Khader and M. A. Morris, Mater. Chem. Phys., 2004, 86, 180-188.

51 K. Hayashi, P. V. Sushko, Y. Hashimoto, A. L. Shluger and H. Hosono, Nat. Commun., 2014, 5, 3515.

52 M. S. Conradi, M. P. Mendenhall, T. M. Ivancic, E. A. Carl, C. D. Browning, P. H. L. Notten, W. P. Kalisvaart, P. C. M. M. Magusin, R. C. Bowman, S.-J. Hwang and N. L. Adolphi, J. Alloys Compd., 2007, 446-447, 499-503.

53 V. S. Kasperovich, M. G. Shelyapina, B. Khar'kov, I. Rykov, V. Osipov, E. Kurenkova, N. E. Skryabina, D. Fruchart, S. Miraglia and P. de Rango, J. Alloys Compd., 2011, 509S, S804-S808. 